DI

Dept of Sleep Medicine, Royal Infirmary Edinburgh, Edinburgh, UK.

\title{
Breathe: biomedical engineering in respiratory disorders
}

This issue is dedicated to technological advances and their contribution to the advancement of respiratory medicine. Our understanding of the fundamental aspects of breathing and respiration would not have been possible without simultaneous advances in technology based in the physical, engineering and chemical sciences. From the Lavoisiers to Boyle, the Curies to Röntgen, without the equipment to conduct the necessary experiments, we would have proceeded even more slowly towards our grasp of oxygen, Boyle's law, the chest radiograph and the fundamental principles of tumour irradiation. As far as respiratory physiology goes, WEST [1] has eloquently stated that surges in our understanding often occur during times of war, when challenges to human physiology spur on technological innovation. War can also create conditions during which talented individuals set aside their different research interests and collaborate effectively. However, technological advances also occur outwith such an environment and in the last three decades, the digital revolution, the Internet, and a number of key discoveries in the biomechanical and engineering fields have revolutionised our approach to evaluating, diagnosing and managing medical disorders. We hope that you will enjoy reading and learning more about ultrasonography and its application to diagnosing diseases of the pleural space and lungs, technical innovations in noninvasive ventilationand our online exclusive on wearable technology and the Internet of Things.

Physiology Masterclass will be available as an online exclusive for this issue: please look out for an unique take on the use of tracheal sound in diagnosing upper airway obstruction during sleep.

We also draw your attention to excellent feature on difficult patient-physician interactions, which I encourage you to read and share. Those of us who have been on both sides of such a conversation will maybe understand the issues even more keenly.

We update each issue of Breathe with exclusive online content, so please come back to us to read and share this material (breathe.ersjournals.com), and don't forget to send in your case reports.

My thanks, as ever, go to our generous contributors, all members of the editorial office and to you, the readers, who contribute to the journal's ongoing success. Wishing you warm and sunny days full of interesting reading!

\section{Conflict of interest}

None declared.

\section{References}

1. West JB ed. Respiratory Physiology: People and Ideas. American Physiological Society. Oxford, Oxford University Press, 1996.

Cite as: Riha RL. Breathe: biomedical engineering in respiratory disorders. Breathe 2017; 13: 75. 